\title{
Time-wise variation of scouring at bridge abutments
}

\author{
A MELIH YANMAZ and OMER KOSE \\ Middle East Technical University, Civil Engineering Department, 06531, \\ Ankara-Turkey \\ e-mail: myanz@metu.edu.tr
}

MS received 23 March 2006; revised 19 July 2006

\begin{abstract}
Accurate estimation of the maximum possible depth of scour at bridge abutments is important in decision-making for the safe depth of burial of footings. Besides, investigation of the geometric features of scour holes around abutments provides useful information for the degree of scour counter-measure to be implemented against excessive scouring. Experiments have been performed to investigate time-dependent characteristics of scour holes around vertical wall abutments under clear water conditions with uniform bed materials. Temporal variations of scour depth and scour contours were measured. Using this information, an empirical relation was developed for temporal variation of scour depth. Additional relations were also derived for time-dependent volume and surface area of the scour holes around abutments. The findings of this study may provide useful information for preliminary design of abutment footings and placement details of armoring counter-measures, such as riprap.
\end{abstract}

Keywords. Bridge abutment; scour depth; riprap; scour holes; river engineering.

\section{Introduction}

River engineering literature has many examples of bridge failures induced by excessive scouring around infrastructural elements. In spite of significant advances in the investigation of scouring phenomenon at bridge elements, studies on time-dependent analysis of scouring at abutments, development of design guidelines for scour counter-measures, etc. are limited. This paper focuses on time-dependent analysis of scouring properties of vertical wall abutments.

The design of bridge foundations on the basis of equilibrium clear water scour depths may yield considerably greater values than if the flow is of short duration. For a known time-to-peak value of design flood hydrograph, smaller scour depths may be obtained, which reduce the total cost of construction (Yanmaz \& Altinbilek 1991). Therefore, investigation of temporal variation of clear water scour at bridge elements is important to estimate the possible extension of the scour hole. This would provide useful information for safe design of footing and the selection of scour counter-measure to be implemented. The degree of severity of the problem is dictated by the magnitude of this scour hole. 
The close upstream of a bridge abutment is subject to a strong pressure field, which leads to the separation of flow, formation of downflow, and primary vortices, which migrate downstream past the abutment. Hence, primary vortices and wake vortices scour the loose bed yielding the development of a scour hole around the abutment.

The depth of scour $\left(d_{s}\right)$ at an abutment is influenced by the abutment length perpendicular to the flow direction $(L)$, the mean approach flow velocity $(u)$, water density $(\rho)$, sediment density $\left(\rho_{s}\right)$, kinematic viscosity of water $(v)$, mean approach threshold velocity $\left(u_{c}\right)$, gravitational acceleration $(g)$, approach water depth $(y)$, median sediment size $\left(D_{50}\right)$, geometric standard deviation of particle size distribution $\left(\sigma_{g}\right)$, abutment shape $\left(K_{s}\right)$, approach channel geometry $\left(K_{G}\right)$, and time $(t)$. Dimensionless parameters can be generated using Buckingum's- $\pi$ theorem. After modifying the dimensionless parameters to end up with more practical results, one obtains

$$
\frac{d_{s}}{L}=f\left(\operatorname{Re}, F_{d}, \frac{u}{u_{c}}, \frac{L}{D_{50}}, \frac{L}{y}, \sigma_{g}, K_{s}, K_{G}, T_{s}\right),
$$

where Re is the Reynold's number, $u y / v, F_{d}$ is the densimetric particle Froude number, $u /\left(\Delta g D_{50}\right)^{0 \cdot 5}, \Delta=\left(\rho_{s}-\rho\right) / \rho$ (relative density); $T_{s}$ is the dimensionless time parameter, which is taken $t D_{50}\left(\Delta g D_{50}\right)^{0 \cdot 5} / L^{2}$ as used by Yanmaz \& Altinbilek (1991). Some of the terms in (1) may be ignored under the following particular conditions. For fully developed turbulent flow, the effect of Reynold's number is negligible. Furthermore, the effect of $L / D_{50}$ term on the scour development diminishes for $L / D_{50}>25$, which reflects most of the actual proto-type conditions (Melville \& Coleman 2000). Therefore, for a given type of abutment mounted in the main channel with negligible floodplains under clear water conditions having uniform bed material, (1) reduces to

$$
\frac{d_{s}}{L}=f\left(F_{d}, \frac{u}{u_{c}}, \frac{L}{y}, T_{s}\right) .
$$

Most of the previous studies were carried out for equilibrium conditions for which the effect of time is neglected (Yanmaz 2002).

Empirical clear water scour equations reported in literature are generally based on equilibrium conditions, which may be achieved in several days in a laboratory medium. According to Lim (1997) the required time to reach the equilibrium scour at abutments in clear water scour is 3-8 days, depending on the flow and sediment conditions. Melville \& Chiew (1999) defined the time to reach equilibrium conditions such that the rate of increase of scour depth does not exceed $5 \%$ of the pier diameter in the succeeding $24 \mathrm{~h}$ period. Besides, Yanmaz \& Altınbilek (1991) and Mia \& Nago (2003) presented semi-empirical models for temporal variation of clear water scour at cylindrical piers. The latter three models require also very long duration for equilibrium situations. Coleman et al (2003) proposed the following expression for temporal variation of scour at vertical wall abutments.

$$
\frac{d_{s}}{d_{s e}}=\exp \left[-0.07\left(\frac{u}{u_{c}}\right)^{-1}\left|\ln \left(\frac{t}{t_{e}}\right)\right|^{1.5}\right],
$$

where $d_{s e}$ is the equilibrium scour depth at an abutment and $t_{e}$ is the time to develop equilibrium scour depth. The equilibrium depth of scour, $d_{s e}$, at a vertical abutment mounted in a main channel composed of uniform bed material can be determined from (Melville \& Coleman 2000)

$$
d_{s e}=K_{y L} K_{I} K_{d}
$$


where $K_{y L}$ is a factor accounting for the effects of flow depth and abutment length, $K_{I}$ is the flow intensity factor which can be taken as $u / u_{c}$ for clear water conditions in uniform bed material, and $K_{d}$ is a factor reflecting the effects of abutment length and particle size. For $L / D_{50}>60$, the value of $t_{e}$ in seconds is determined from (Coleman et al 2003)

$$
\begin{aligned}
& t_{e}=10^{6}\left(\frac{L}{u}\right)\left\{3-\left[1 \cdot 2\left(\frac{y}{L}\right)\right]\right\} \text { for } y / L<1, \\
& t_{e}=1 \cdot 8^{*} 10^{6}\left(\frac{L}{u}\right)\left(\frac{u}{u_{c}}\right)^{3} \text { for } y / L \geq 1 .
\end{aligned}
$$

The precision of time-dependent scour depths given by (3) is influenced by the accuracy of equilibrium parameters. However, results obtained from different equations dealing with equilibrium scour may differ widely (Yanmaz, 2002). The following equation was derived by Oliveto \& Hager (2002) for time-dependent scour depth at vertical wall abutments under clear water conditions

$$
d_{s} / L_{R}=0.085 \sigma_{g}^{-0 \cdot 5} F_{d}^{1 \cdot 5} \log T_{d}
$$

in which $L_{R}=L^{2 / 3} y^{1 / 3}, T_{d}=t / t_{R}$, and $t_{R}=L_{R} /\left(\Delta g D_{50}\right)^{0.5}$. Contrary to the Coleman et al (2003) approach, (7) does not require equilibrium scouring parameters. Time variation of scour depth at bridge abutments have also been studied by several other investigators, such as Wong 1982, Tey 1984, Hoffmans \& Verheij 1997, Cardoso \& Bettess 1999, Ballio \& Orsi 2001, Kothyari \& Ranga Raju 2001, Santos \& Cardoso 2001, Dey \& Barbhuiya 2005, and Oliveto \& Hager 2005. In spite of availability of a number of abutment scour-prediction equations in the literature, there is no single analytically derived equation, which is valid for wide range of flow conditions, bed material properties, and abutment shape configurations, because of difficulties of precise modelling of the phenomenon in a laboratory medium. Lack of understanding of complex flow conditions and simplified modelling of the phenomenon, would lead to pronounced modelling uncertainty (Yanmaz \& Cicekdag 2001). On the other hand, reliable field data are scarce leading to calibration problems (Yanmaz \& Altinbilek 1991). Therefore, engineering solutions concerning determination of safe depth of burial of footing and selection of scour counter-measures would be subject to uncertainty. To offset this problem, additional experimental studies need to be conducted. The objective of this study is to investigate the temporal variation of the geometric characteristics of scour holes around vertical wall abutments using the scour contours, which were determined through a set of laboratory experiments.

\section{Experimental procedure}

The experiments were carried out in a flume of $30 \mathrm{~m}$ long, $1.25 \mathrm{~m}$ wide, and $1.0 \mathrm{~m}$ deep. The median sizes of the bed materials were $1.8 \mathrm{~mm}$ and $0.9 \mathrm{~mm}$ with a geometric standard deviation of approximately 1.40 . Bed materials were placed as a $40 \mathrm{~cm}$ thick layer in the flume bed with a bed slope of 0.001. To investigate the effect of abutment size, plexiglas abutment models with lengths of $12.5 \mathrm{~cm}$ and $10 \mathrm{~cm}$ having a constant width of $20 \mathrm{~cm}$ were tested. The scope of the experiments is given in table 1. In the experiments, the maximum scour depths around the abutment were measured against time relative to the initial bed level using a vertical scale attached to the interior of hollow plexiglas abutment with a stick having 
Table 1. Scope of experiments.

\begin{tabular}{|c|c|c|c|c|c|c|}
\hline Run no. & $L(\mathrm{~cm})$ & $D_{50}(\mathrm{~mm})$ & $u / u_{c}$ & $y(\mathrm{~cm})$ & $t_{\max }(\min )$ & $T_{s}$ \\
\hline 1 & 12.5 & 1.8 & 0.777 & 8.9 & 360 & 424.7 \\
\hline 2 & 12.5 & 1.8 & 0.751 & $8 \cdot 3$ & 360 & 424.7 \\
\hline 3 & 12.5 & 1.8 & 0.741 & 7.5 & 360 & 424.7 \\
\hline 4 & 12.5 & 1.8 & 0.713 & $6 \cdot 8$ & 360 & 424.7 \\
\hline 5 & 12.5 & 1.8 & 0.682 & $6 \cdot 1$ & 360 & 424.7 \\
\hline 6 & 12.5 & 1.8 & 0.777 & 8.9 & 5 & 5.9 \\
\hline 7 & 12.5 & 1.8 & 0.777 & 8.9 & 20 & $23 \cdot 6$ \\
\hline 8 & 12.5 & 1.8 & 0.777 & 8.9 & 60 & 70.8 \\
\hline 9 & 12.5 & 1.8 & 0.777 & 8.9 & 100 & $118 \cdot 0$ \\
\hline 10 & 12.5 & 1.8 & 0.777 & 8.9 & 150 & $177 \cdot 0$ \\
\hline 11 & 10 & 1.8 & 0.777 & 8.9 & 360 & $663 \cdot 6$ \\
\hline 12 & 10 & 1.8 & 0.751 & $8 \cdot 3$ & 360 & $663 \cdot 6$ \\
\hline 13 & 10 & 1.8 & 0.741 & 7.5 & 360 & $663 \cdot 6$ \\
\hline 14 & 10 & 1.8 & 0.713 & $6 \cdot 8$ & 360 & 663.6 \\
\hline 15 & 10 & 1.8 & 0.777 & 8.9 & 5 & $9 \cdot 2$ \\
\hline 16 & 10 & 1.8 & 0.777 & 8.9 & 20 & $36 \cdot 9$ \\
\hline 17 & 10 & 1.8 & 0.777 & 8.9 & 60 & $110 \cdot 6$ \\
\hline 18 & 10 & 1.8 & 0.777 & 8.9 & 100 & $184 \cdot 3$ \\
\hline 19 & 10 & 1.8 & 0.777 & 8.9 & 150 & 276.5 \\
\hline 20 & 12.5 & 0.9 & 0.985 & $5 \cdot 2$ & 360 & $150 \cdot 2$ \\
\hline 21 & 12.5 & 0.9 & 0.899 & 4.4 & 360 & $150 \cdot 2$ \\
\hline 22 & 10 & 0.9 & 0.985 & $5 \cdot 2$ & 360 & $234 \cdot 6$ \\
\hline 23 & 10 & 0.9 & 0.899 & 4.4 & 360 & $234 \cdot 6$ \\
\hline
\end{tabular}

a small inclined mirror at its end. Temporal variation of scour depths is presented in figures 1 and 2 for the bed materials tested. As indicated earlier, a long duration is required to reach the equilibrium state under clear water conditions. However, from a practical standpoint, it is difficult to perform a wide range of experiments with such a long duration. Therefore, the test duration of an experiment, $t_{\max }$, was limited to six hours during which the final equilibrium scour depths were not achieved although the rate of scour did decelerate to smaller values for all experiments.

The experiments were aimed at observing time-dependent variation of the shapes of scour holes including the location and magnitudes of maximum scour depths around the abutments. To investigate scour contours, experimental runs 6-10 and 15-19 were performed with a densimetric particle Froude number of 2.38 for the abutments tested. Scour contours were obtained only for this constant value of $F_{d}$. Other values of $F_{d}$ were not tested because of fundamental similarity of all local scouring situations. Experiments were stopped at the end of different test durations, namely 5, 20,60, 100, and $150 \mathrm{~min}$ to determine the contours of scour hole around abutment models using point gages. At the end of each experiment, water was carefully removed from the channel so as not to disturb the bed topography and measurements were carried out in a grid system around the abutment composed of joints separated by $2 \mathrm{~cm}$ intervals along and across the channel. After each run, the bed was flattened to run the experiment with the next duration. Time-dependent scour contours were then obtained for the abutments tested. Figure 3 shows the scour contours around the vertical wall abutment with $L=12.5 \mathrm{~cm}$ obtained at the end of $150 \mathrm{~min}$ of test duration. 


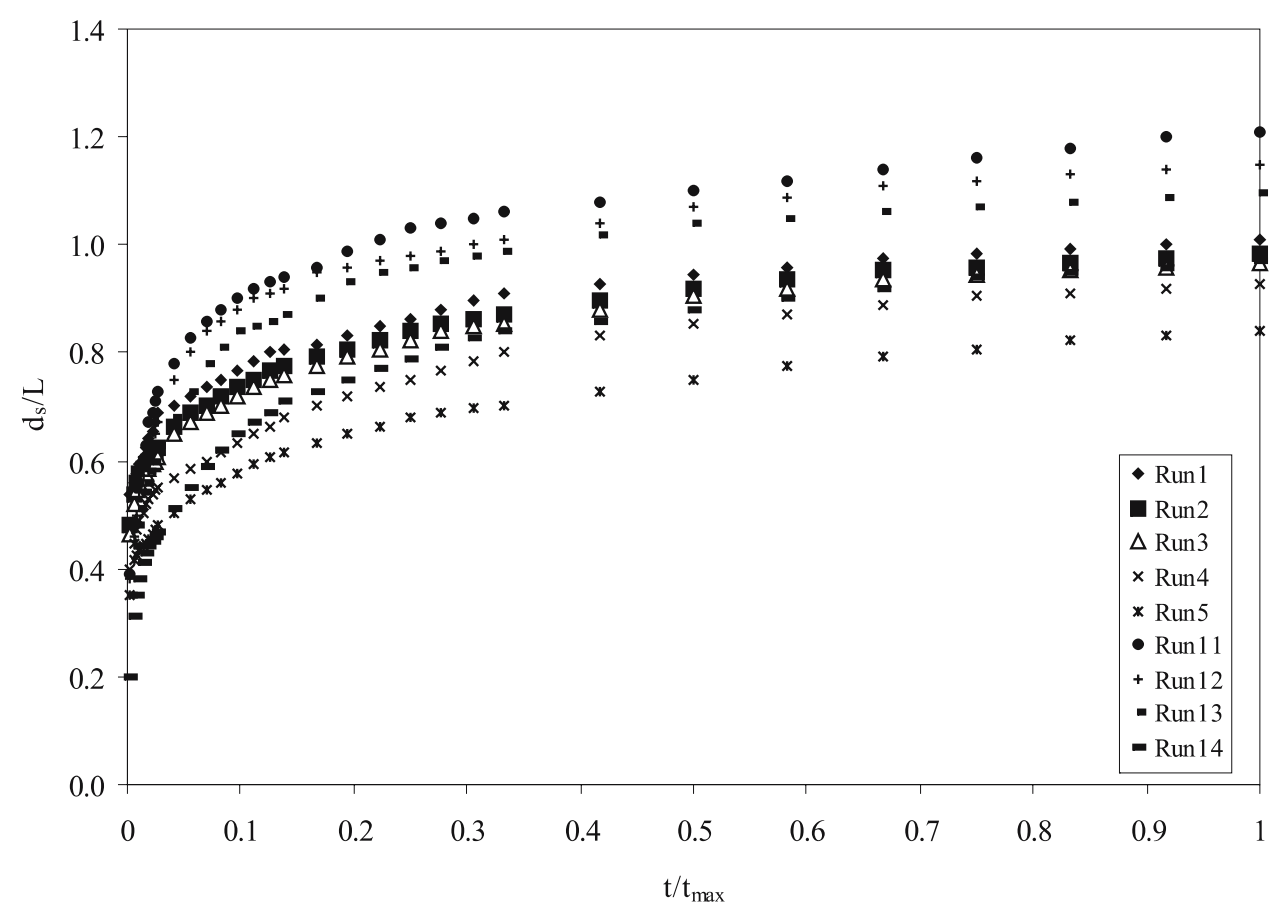

Figure 1. Variation of scour depth against time for $D_{50}=1.8 \mathrm{~mm}$.

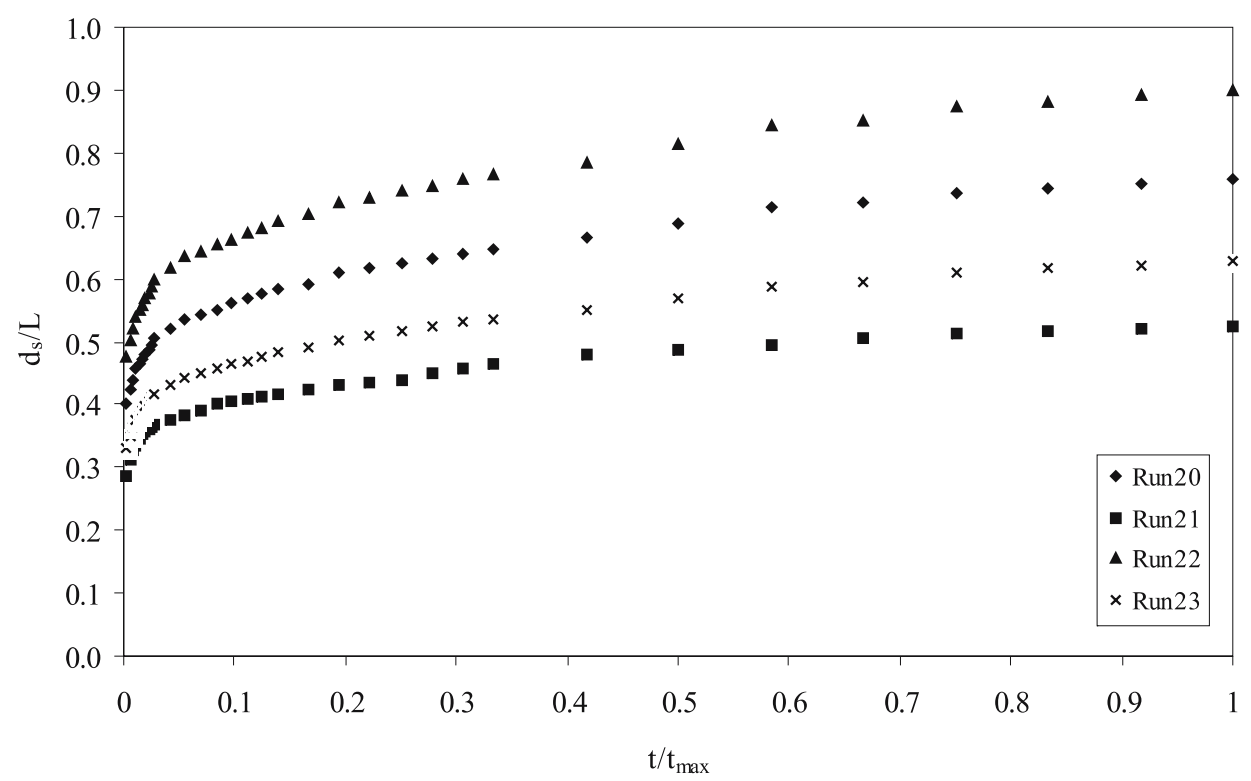

Figure 2. Variation of scour depth against time for $D_{50}=0.9 \mathrm{~mm}$. 


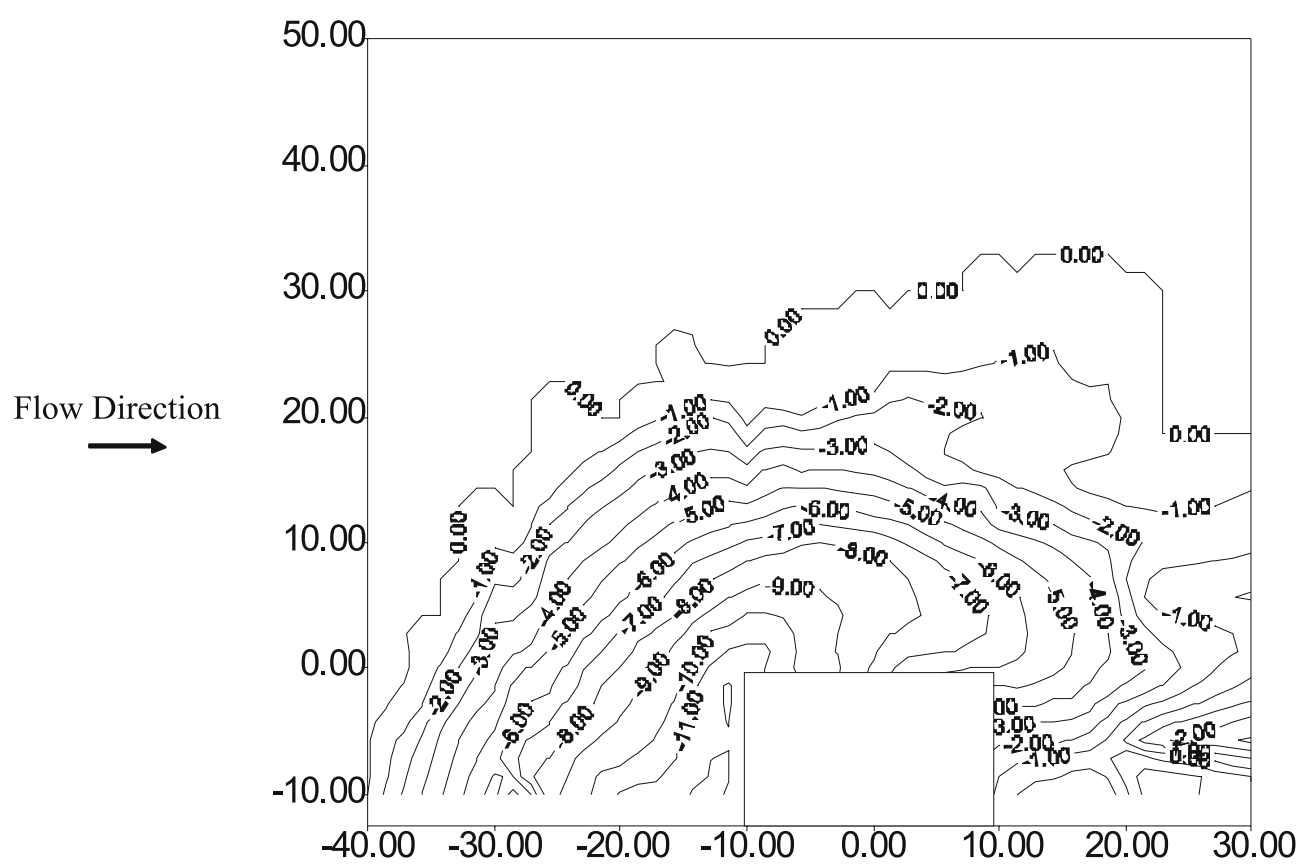

Figure 3. Contours of scour hole in $\mathrm{cm}$ around vertical abutment at $t=150 \mathrm{~min}$.

\section{Analysis of experimental results}

This study deals with two consecutive analyses. In the first part, temporal variation of the scour depth around the abutment was examined. In the second phase, the geometric characteristics of the scour hole was investigated. With further interpretation of the scouring parameters listed in (2), it can be observed that $u / u_{c}$ and $F_{d}$ would essentially reflect similar information concerning flow depth, bed slope, bed resistance characteristics, and median sediment size. That was why the effects of $u / u_{c}$ and $F_{d}$ on the scour depth were examined separately keeping the other variables in the analysis. After a number of trials using the experimental data presented in figures 1 and 2, equation (8), giving the best trend compared to the other possible cases, is eventually proposed:

$$
d_{s} / L=0.25 F_{d}^{0 \cdot 85}(L / y)^{0 \cdot 15}\left(\log T_{s}\right)^{0 \cdot 60}
$$

Equation (8) is plotted together with some experimental runs to observe its predictive ability and agreement with methods proposed by Coleman et al (2003) and Oliveto \& Hager (2002). The results of this analysis are shown in figure 4 for some experimental runs. Furthermore, correlations between experimental $\left(d_{s e x}\right)$ and computed $\left(d_{s c}\right)$ scour depths were also obtained using the afore-mentioned equations. In order to interpret the overall results of the analysis on a quantitative basis, the equations proposed by Coleman et al (2003), Oliveto \& Hager (2002), and the present study, i.e. equations (3), (7), and (8) were applied to all experimental runs and a prediction factor, $r=d_{s c} / d_{s e x}$, was defined. The average $r$-values were obtained as 0.78 , $1 \cdot 14$, and 1.03 using (3), (7), and (8) respectively. The average tendency in the range of the experiments conducted implies that (8) predicts time-dependent scour depths with relatively good agreement since it yielded an $r$-value, which is closest to unity. Similarly, the average 

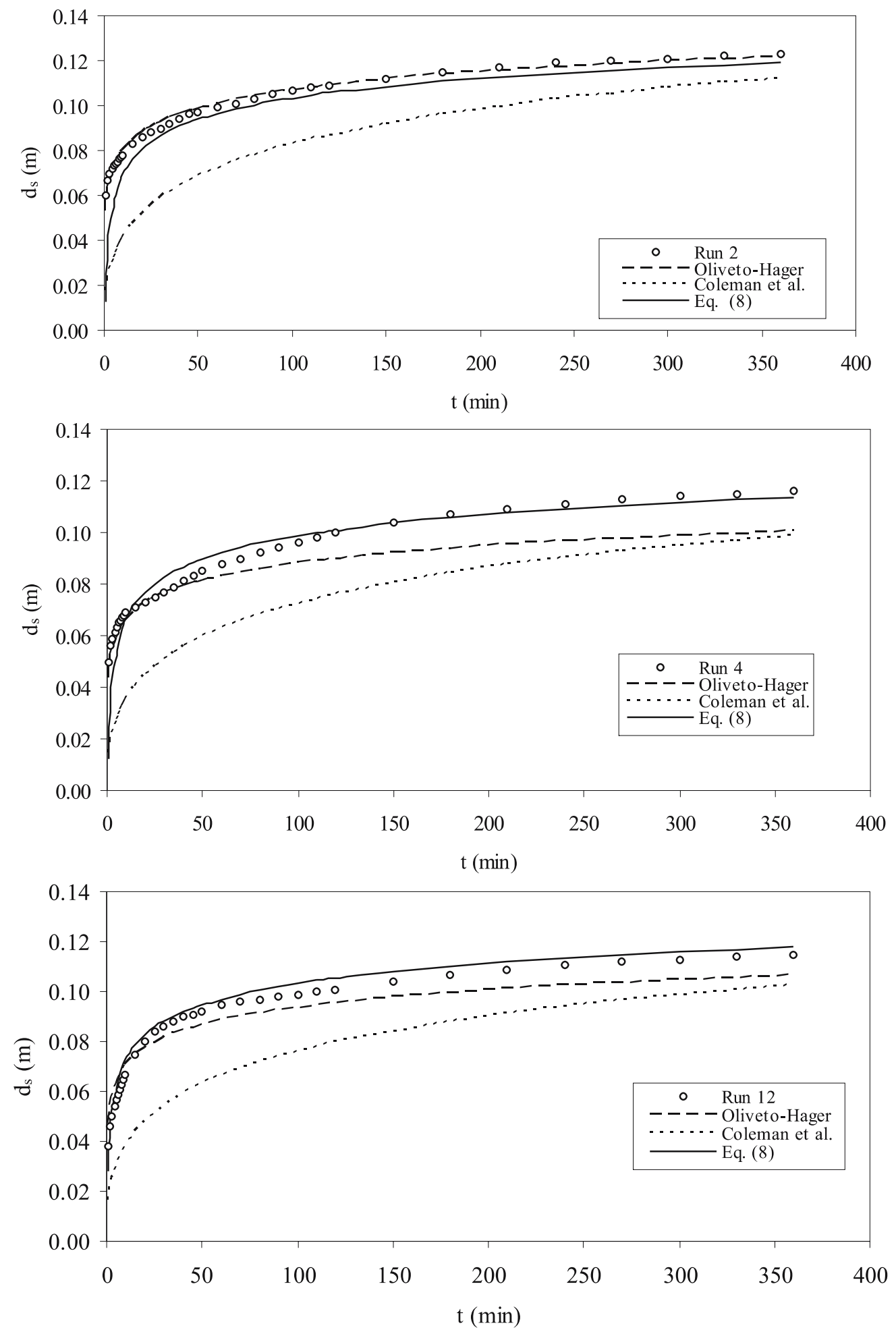

Figure 4. Comparison of equation 8 with experimental runs 2, 4, 12, and other methods. 
tendency of the Oliveto-Hager (2002) approach is to yield slightly greater scour depths, whereas the equation proposed by Coleman et al (2003) gives somewhat smaller scour depths than the experimentally observed values. However, this conclusion needs further verification, i.e., the validity of (8) and its agreement with the methods of Coleman et al (2003) and OlivetoHager (2002) may be tested in a future study using different flow, sediment, and abutment properties than the ranges considered in this study. Further remarks on the applicability of (8) are presented in the following paragraphs.

Practical interest of (8) is dependent on the range of dimensionless time term, $T_{s}$ whose maximum experimental value is 663.6 (table 1). Equation (8) is valid in the range, $1.12 \leq$ $L / y \leq 2 \cdot 84$. A hypothetical example is presented to give some guides concerning proto-type applications under clear water conditions using values, which are of practical interest. Let us assume that a bridge is to be constructed at a floodplain where the river-bed is composed of uniform cohesionless material having $D_{50}=15 \mathrm{~mm}$ on a slope of 0.0006 . The design approach flow depth is $1.5 \mathrm{~m}$. A vertical abutment of $L=3.0 \mathrm{~m}$ will be used. These values yield, $L / y=2.0, u_{* c}=0.12 \mathrm{~m} / \mathrm{s}$, and $u_{*}=0.094 \mathrm{~m} / \mathrm{s}$ where $u_{* c}$ is the critical shear velocity based on Shields criterion and $u_{*}$ is the shear velocity, respectively. Therefore, clear water conditions prevail at the site. If the maximum value of $T_{s}=663.6$ is considered, it corresponds to a flood duration of $t=225 \mathrm{hr}$ or 9.4 days. This duration can be taken as the time-to-peak of the design flood, which is sufficiently long for most watersheds. This example clearly illustrates that (8), derived using experimental values of $T_{s}$, may be valid even for sufficiently long time to peak values of proto-type floods.

Another aspect to be discussed is the scale effects. Similitude of scour depth requires that $F_{r}, u / u_{c}$, and $L / y$ values should be the same for both flume and proto-type. Flume experiments, however, are normally forced to use bed materials, which have comparable sizes as the proto-type since very fine particles in the laboratory medium would be subject to suspension. Therefore, to maintain similar modes of sediment transportation, greater values of $u$ required than in Froude number simulation are needed in a laboratory medium. Hence, the Froude number used in laboratory experiments may be greater than that for the corresponding field conditions. On the other hand, it is known that clear water scour depth increases with increasing Froude number (Melville \& Coleman 2000). Therefore, it may be concluded that empirical scour-prediction equations, like (8), are conservative in nature, i.e. they may overestimate the scour depths.

In the second phase of the analysis, the geometric characteristics of the scour holes around the abutment were investigated. In order to observe the locations of the maximum depths of scour and accretion around abutment models, the coordinate system shown in figure 5 was used. For comparison, the surrounding of the abutment models was divided into 6 regions. During the experiments, it was observed that maximum scour depths occurred in region 1 , whereas the maximum accretions were observed in region 5. It was also observed that the horizontal distance between the locations of maximum depths of scour and accretion decreased with decreasing length of vertical wall abutment.

To achieve relevant information for the geometric characteristics of the scour hole, the rate of change of the scour hole volume needs to be investigated with reference to the coordinate system shown in figure 5 . To this end, the cross-sections $\mathrm{A}-\mathrm{A}, \mathrm{B}-\mathrm{B}$, and $\mathrm{C}-\mathrm{C}$ were taken. The coordinate system was placed at the top of the scour hole (figure 5). The coordinates $x^{\prime}$ and $y^{\prime}$ were along the sections $\mathrm{A}-\mathrm{A}$ and $\mathrm{B}-\mathrm{B}$, respectively, whereas the $z^{\prime}$-coordinate was located downward along the face of the abutment. To determine the rate of change of side inclination of the scour hole, an analysis was carried out in which $X^{\prime}, Y^{\prime}$, and $Z^{\prime}$ were accepted as the time-dependent coordinates of the scour hole, whereas $X_{\max }^{\prime}, Y_{\max }^{\prime}$, and $Z_{\max }^{\prime}$ were the 


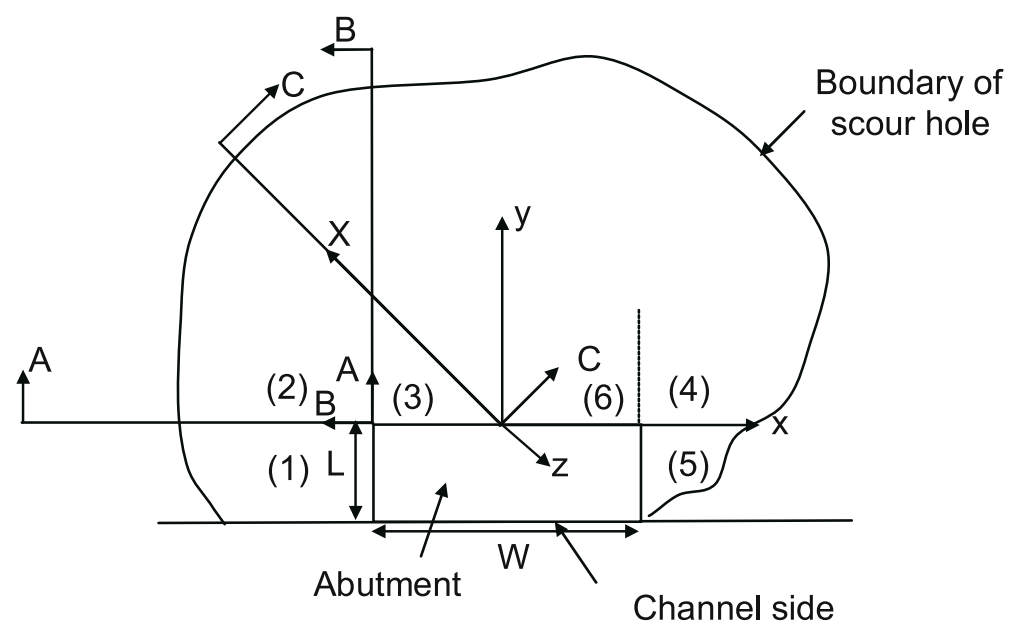

Figure 5. The coordinate system of the scour hole.

maximum coordinates of the scour hole measured at the end of the tests executed with the afore-mentioned test durations. The correlations between $X^{\prime} / X_{\max }^{\prime}-Z^{\prime} / Z_{\max }^{\prime}, Y^{\prime} / Y_{\max }^{\prime}-$ $Z^{\prime} / Z_{\max }^{\prime}$, and $X / X_{\max }-Z^{\prime} / Z_{\max }^{\prime}$ were investigated to examine the rate of change of the side inclination of the scour hole at different axes (figures 6-8). As observed in these figures, the data points lie almost along the bisector line. Similar trends were noticed for the case of abutment with $L=10 \mathrm{~cm}$. Therefore, it can be accepted that the shape of the scour hole remains almost unchanged with respect to time. However, the rate of change decelerates as time elapses.

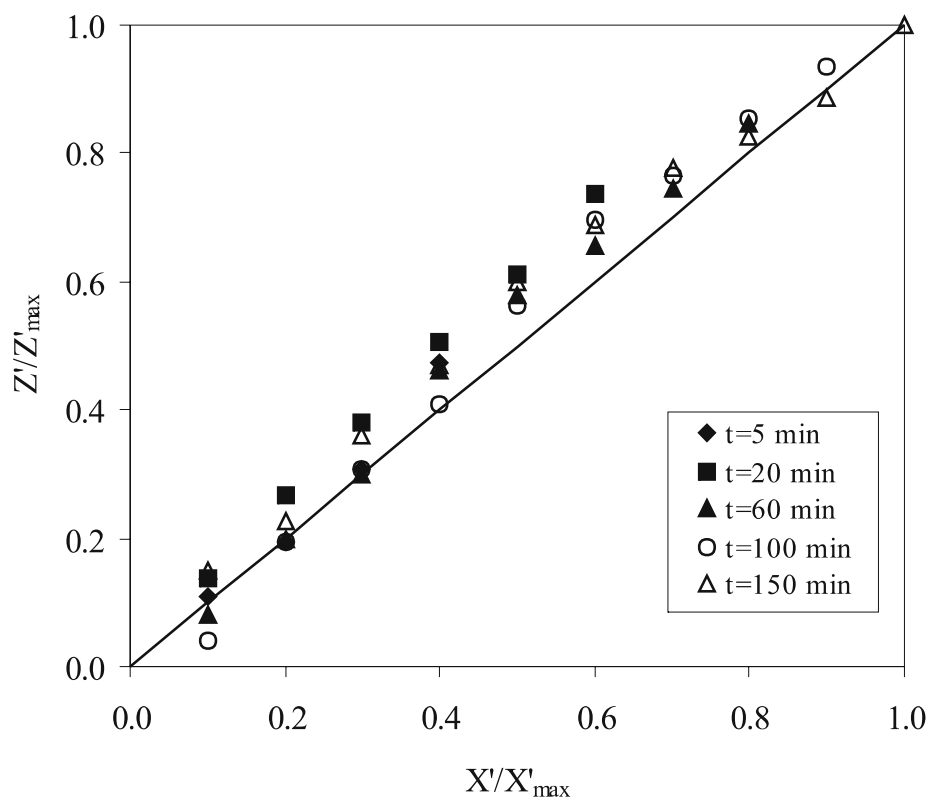

Figure 6. Correlation between $X^{\prime} / X_{\max }^{\prime}$ and $Z^{\prime} / Z_{\max }^{\prime}$ (Section A-A in figure 5). 


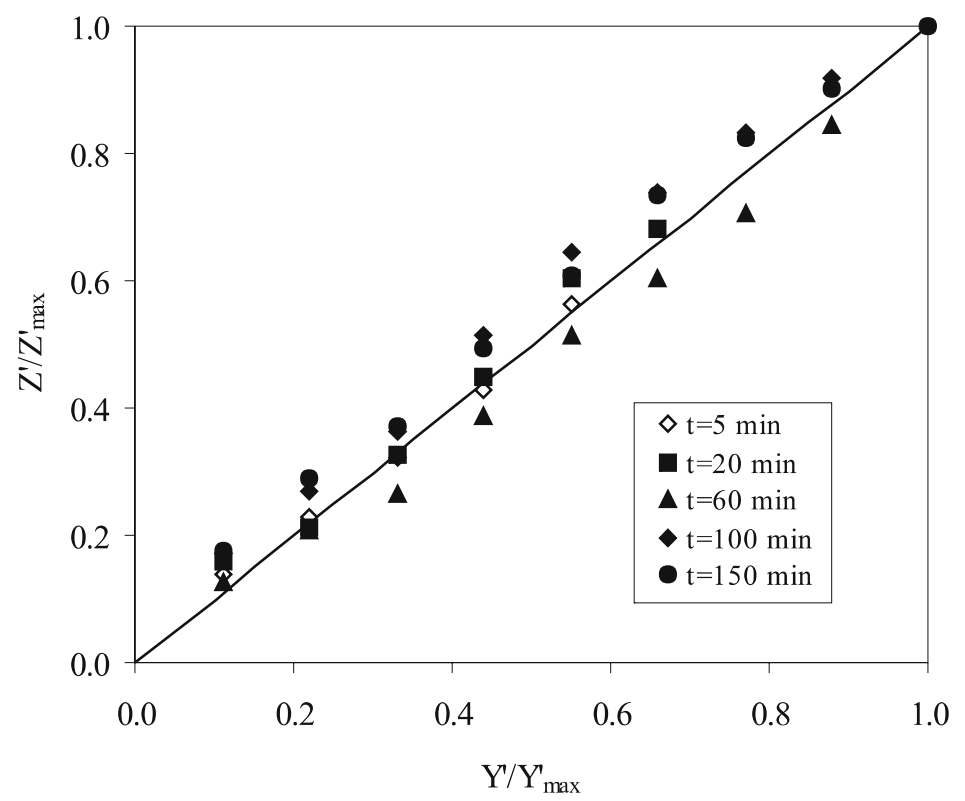

Figure 7. Correlation between $Y^{\prime} / Y_{\max }^{\prime}$ and $Z^{\prime} / Z_{\max }^{\prime}$ (Section B-B in figure 5).

Another by-product of this study was that the side angles of the scour hole, except the rear face of the abutment, was approximately equal to the angle of repose of the sediment. Dey $\&$ Barbhuiya (2005) also observed that the upstream scour holes around abutment models of

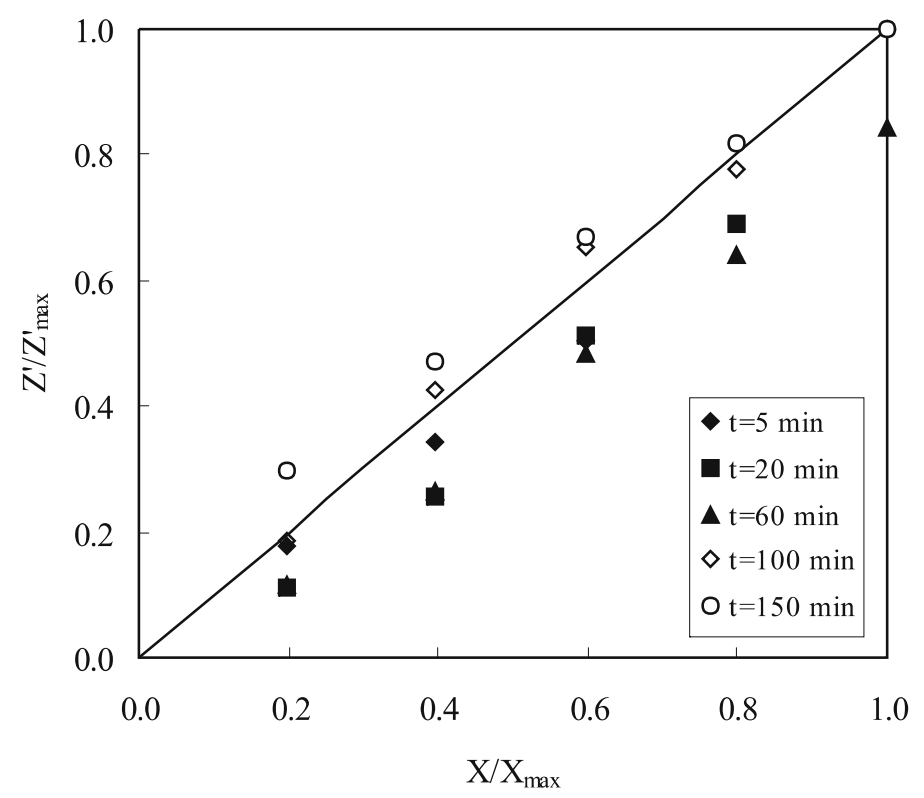

Figure 8. Correlation between $X / X_{\max }$ and $Z^{\prime} / Z_{\max }^{\prime}$ (Section C-C in figure 5). 
different shapes had a similarity at different times. They concluded that this implied a layerby-layer scouring process until an equilibrium state was achieved. As a result of experimental measurements and their interpretation, the volume of the scour hole around a vertical wall abutment is assumed to be approximated by an inverted semi-cone having a rectangular base.

Finally, the volume and surface area of the scour hole around the abutments were computed at the afore-mentioned test durations using a software based on triangularisation technique. This program is capable of evaluating the area and volume elements bounded by irregular contours. For the sake of practical applications, dimensionless scour hole volume and surface area expressions are defined as $V^{*}=V /\left(d_{s} L^{2}\right)$ and $A^{*}=A /(W L)$, respectively, where $V$ is the volume, $A$ is the surface area of the scour hole around the abutment, and $W$ is the width of the abutment parallel to the flow direction. Variations of dimensionless scour area and volume with respect to dimensionless time, $T_{s}$, are shown in figures 9 and 10, respectively. The regression equations fitted to the data points in these figures with the corresponding correlation coefficients $\left(R^{2}\right)$ are obtained as

$$
\begin{aligned}
& A^{*}=3 \cdot 722 T_{s}^{0 \cdot 182}\left(R^{2}=0.962\right), \\
& V^{*}=1 \cdot 142 T_{s}^{0 \cdot 281}\left(R^{2}=0.980\right) .
\end{aligned}
$$

As can be seen from figures 9 and 10, the rates of change of $A^{*}$ and $V^{*}$ decrease with respect to $T_{s}$. The order of magnitude of the time required to reach the equilibrium conditions can be found such that the corresponding rate of change of dimensionless volume is almost zero. In order to have information for the equilibrium value of $T_{s}$ under experimental conditions, the method of Coleman et al (2003) is applied to the data. As a result, a value of $T_{s}=13048$ is obtained, which gives an equilibrium test duration of $184 \mathrm{~h}$. In actual proto-type conditions, the corresponding flow duration would be extremely long for the practical ranges of design flow conditions. With the extrapolation of (9), it can be observed that the rate of change of $A^{*}$ is negligibly small for $T_{s}>4500$. This limiting value gives approximately $A^{*}=17$. In other words, the surface area of the scour hole is about $A=17 \mathrm{WL}$ and its further development is

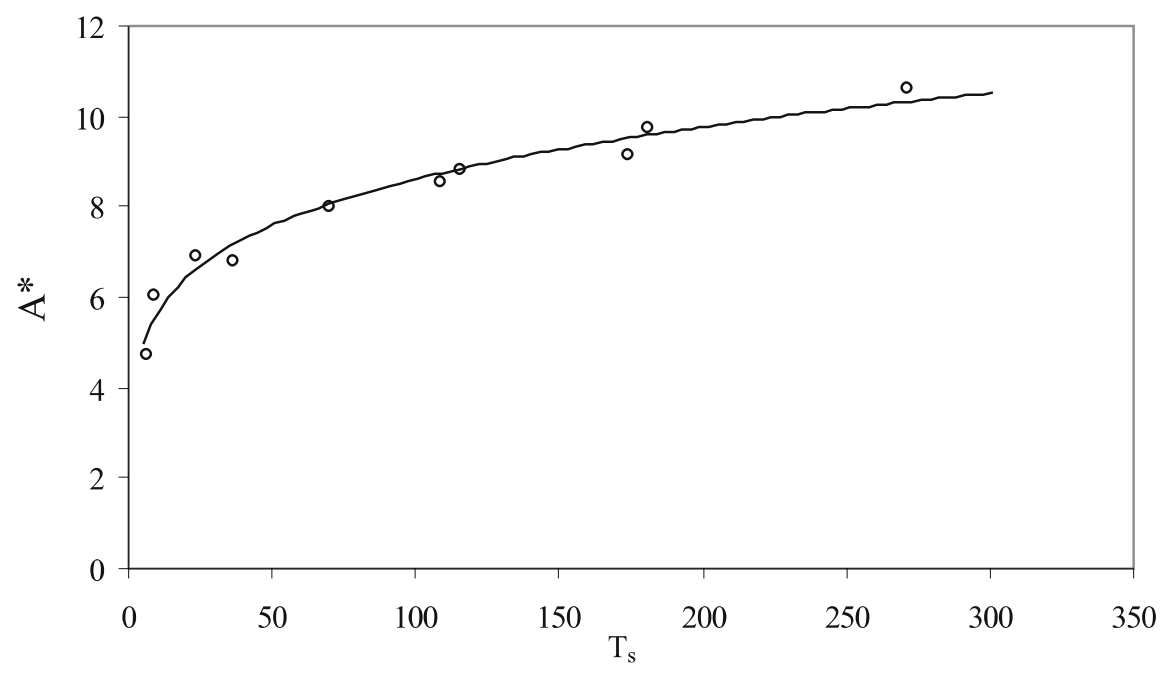

Figure 9. Variation of dimensionless scour area with dimensionless time. 


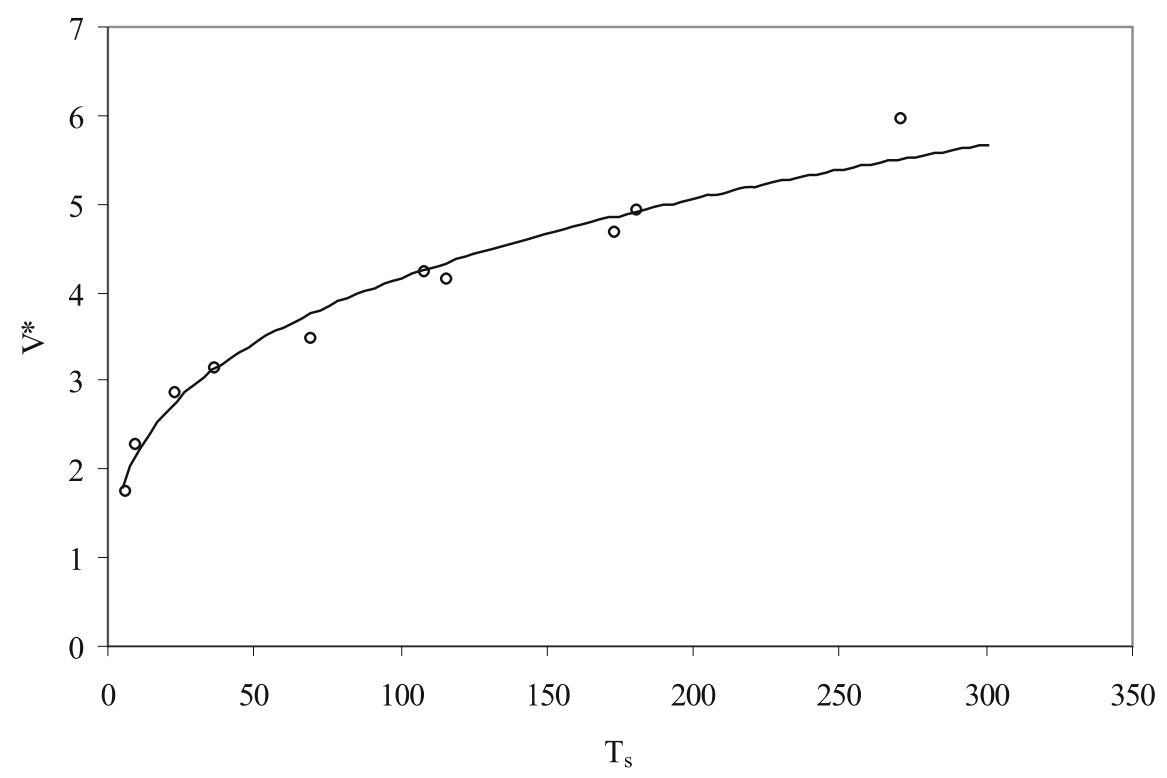

Figure 10. Variation of dimensionless scour volume with dimensionless time.

negligibly small. This value can be used as an approximate area of coverage of the bed with an armoring counter-measure, e.g. riprap.

There exist some methods in the literature giving the appropriate riprap size to be placed around abutments, which are outlined by Melville \& Coleman (2000). However, studies dealing with the placement details of riprap around abutments are limited. Therefore, riprap coverage area of $A=17 W L$ may be used as a preliminary design value. A semi-circular area with the origin shown in figure 11, which is expressed in (11), may be adopted for the riprap coverage at the bed level around the abutment.

$$
A=\frac{\pi}{2}\left(3 \cdot 5 L+\frac{W}{2}\right)^{2}-W L .
$$

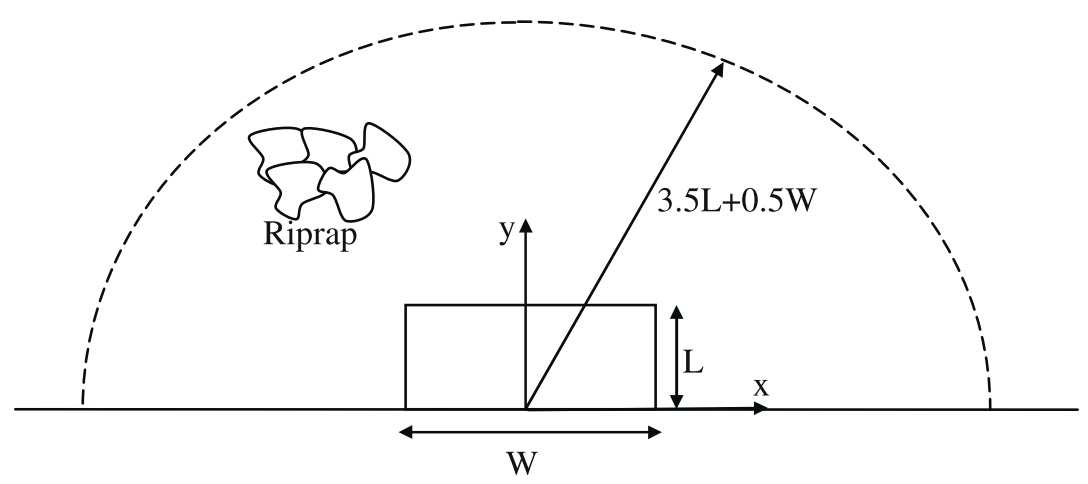

Figure 11. Placement of riprap around abutment as scour counter-measure. 
The suggested placement area of riprap armoring is illustrated in figure 11 . The surface elevation of riprap layer can be placed at the mean bed level or at a lower elevation not to create extra turbulence at the bed. It should be emphasized, however, that additional experiments need to be conducted to generalize the design details of this armoring counter-measure, i.e., the extension of the area of protection as well as the size, layer thickness, and surface elevation of the riprap.

\section{Conclusions}

An experimental study was carried out to observe the time-dependent geometric characteristics of scour holes around vertical wall abutments under clear water conditions with uniform bed materials. This information is needed for determining the safe depth of burial of bridge footings as well as for deciding the degree of protection to be implemented against excessive scouring. During the experiments, it was observed that the maximum scour depths occurred at the upstream face of the abutments, whereas the maximum accretions took place around the rear face of the abutment. It was also observed that the horizontal distance between the locations of maximum depths of scour and accretion decreased with decreasing abutment length. Using the information, an empirical relation was developed for temporal variation of scour depth around vertical wall abutments. Additional empirical relations were also obtained for time-dependent dimensionless volume and surface area of the scour holes around these elements. The latter equations are assumed to provide preliminary design guidelines for deciding the extension of placement of armoring counter-measure around vertical wall abutments. Additional experimental research is required to establish detailed guidelines for such a placement.

The experiments were carried out in Hydraulics Laboratory of the Technical Investigation and Quality Control Department of Turkish State Hydraulic Works, Ankara. The authors are grateful for the support provided by the laboratory staff.

\section{List of symbols}

A surface area of scour hole;

$A^{*} \quad$ dimensionless surface area of scour hole;

$D_{50} \quad$ median sediment size;

$d_{s} \quad$ instantaneous maximum depth of scour at an abutment;

$d_{\mathrm{sc}} \quad$ computed depth of scour at an abutment;

$d_{\text {se }} \quad$ equilibrium depth of scour at an abutment;

$d_{\text {sex }}$ experimental depth of scour at an abutment;

$F_{d} \quad$ densimetric particle Froude number;

$g \quad$ gravitational acceleration;

$K_{d} \quad$ factor to account for the effect of sediment size and abutment length;

$K_{I} \quad$ factor to account for the effect of flow intensity;

$K_{y L}$ factor to account for the effect of abutment length and flow depth;

$L \quad$ abutment length;

$L_{R} \quad$ combined abutment length and flow depth parameter; 
$R \quad$ correlation coefficient;

$r \quad$ prediction factor;

$T_{d} \quad$ dimensionless time term;

$T_{s}$ dimensionless time in the proposed method;

$t$ time;

$t_{R} \quad$ time term;

$t_{e} \quad$ time to reach equilibrium scouring condition;

$t_{\max }$ maximum duration of experiment;

$u \quad$ mean approach flow velocity;

$u_{c}$ mean threshold velocity of approach flow;

$u_{*} \quad$ shear velocity;

$u_{* c} \quad$ critical shear velocity;

$V \quad$ volume of scour hole;

$V^{*} \quad$ dimensionless scour hole volume;

$W \quad$ width of abutment;

$y \quad$ approach flow depth;

$v \quad$ kinematic viscosity of water;

$\rho \quad$ water density;

$\rho_{s} \quad$ sediment density;

$\Delta \quad$ relative density;

$\sigma_{g} \quad$ geometric standard deviation of particle size distribution.

\section{References}

Ballio F, Orsi E (2001) Time evolution of scour around bridge abutments. Water Eng. Res., 2: 243-259

Cardoso A H, Bettess R (1999) Effects of time and channel geometry on scour at bridge abutments. J. Hydraul. Eng., 125: 388-399

Coleman S E, Lauchlan C S, Melville B W (2003) Clear water scour development at bridge abutments, J. Hydraul. Res., 41: 521-531

Dey S, Barbhuiya A K (2005) Time variation of scour at abutments. J. Hydraul. Eng., 131: 11-23

Hoffmans G J C M, Verheij H J (1997) Scour manual, AA Bakema: Rotterdam

Kothyari U C, Ranga Raju K G (2001) Scour around spur dikes and bridge abutments. J. Hydraul. Res., 39: 367-374

Lim S Y (1997) Equilibrium clear-water scour around an abutment. J. Hydraul. Eng., 123: 273-243

Mia M F, Nago H (2003) Design method of time-dependent local scour at circular bridge pier. $J$. Hydraul. Eng., 129: 420-427

Melville B W, Chiew Y M (1999) Time scale for local scour at bridge piers. J. Hydraul. Eng., 125: 59-65

Melville B W, Coleman S E (2000) Bridge scour, Water Resources Publications: Highlands Ranch, Colorado

Oliveto G, Hager W H (2002) Temporal evolution of clear water pier and abutment scour. J. Hydraul. Eng., 128: 811-820

Oliveto G, Hager W H (2005) Further results to time-dependent local scour at bridge elements. $J$. Hydraul. Eng., 131: 97-105

Santos J S, Cardoso A H (2001) Time evolution of local scour at obstacles protruding from channel side walls. Int. J. Sediment Res., 16: 460-472

Tey C B (1984) Local scour at bridge abutments, Report No. 329, School of Engineering, Univ. of Auckland, Auckland 
Wong W H (1982) Scour at bridge abutments, Report No. 275, School of Engineering, University of Auckland, Auckland

Yanmaz A M and Altınbilek H D (1991) Study of time dependent local scour around bridge piers. $J$. Hydraul. Eng., 117: 1247-1268

Yanmaz A M, Cicekdag O (2001) Composite reliability model for local scour around cylindrical bridge piers. Can. J. Civ. Eng., 28: 520-535

Yanmaz A M (2002) Bridge hydraulics. METU Press Publications: Ankara, (in Turkish) 